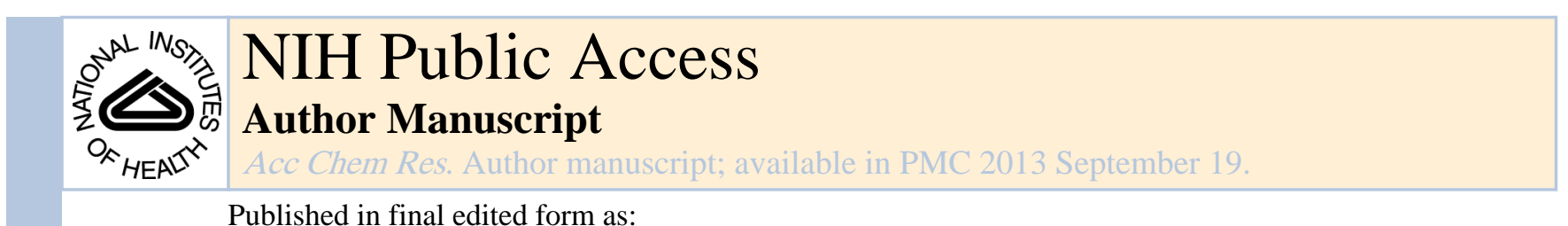

Acc Chem Res. 2011 October 18; 44(10): 957-968. doi:10.1021/ar200028a.

\title{
Nanoscale Metal-Organic Frameworks for Biomedical Imaging and Drug Delivery
}

\author{
JOSEPH DELLA ROCCA, DEMIN LIU, and WENBIN LIN ${ }^{\star}$ \\ Department of Chemistry, CB\#3290, University of North Carolina at Chapel Hill, Chapel Hill, \\ North Carolina 27599, United States
}

\section{CONSPECTUS}

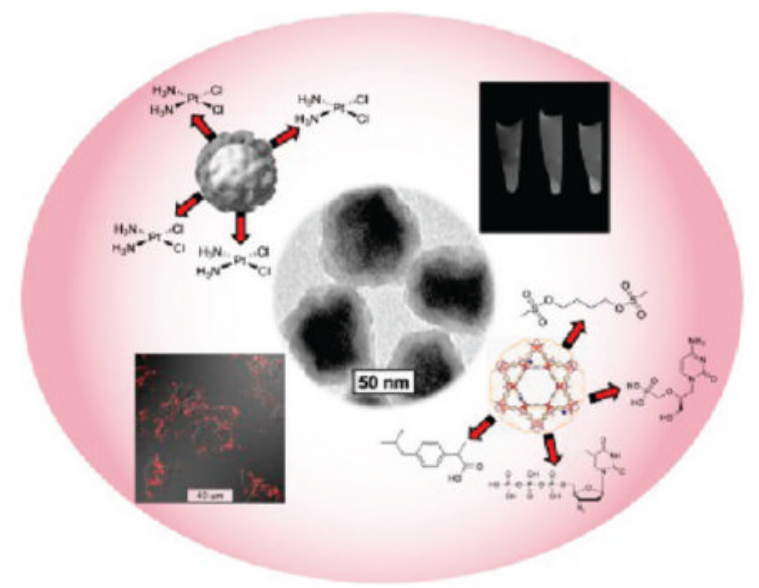

Metal-organic frameworks (MOFs), a class of hybrid materials formed by the self-assembly of polydentate bridging ligands and metal-connecting points, have been studied for a variety of applications. Recently, these materials have been scaled down to nanometer sizes, and this Account details the development of nanoscale metal-organic frameworks (NMOFs) for biomedical applications. NMOFs possess several potential advantages over conventional nanomedicines such as their structural and chemical diversity, their high loading capacity, and their intrinsic biodegradability. Under relatively mild conditions, NMOFs can be obtained as either crystalline or amorphous materials. The particle composition, size, and morphology can be easily tuned to optimize the final particle properties. Researchers have employed two general strategies to deliver active agents using NMOFs: by incorporating active agents into the frameworks or by loading active agents into the pores and channels of the NMOFs. The modification of NMOF surfaces with either silica coatings or organic polymers improves NMOF stability, fine-tunes their properties, and imparts additional functionality.

Preliminary biomedical applications of NMOFs have focused on their use as delivery vehicles for imaging contrast agents and molecular therapeutics. Because NMOFs can carry large amounts of paramagnetic metal ions, they have been extensively explored as magnetic resonance imaging (MRI) contrast agents. Both $\mathrm{Gd}^{3+}$ - and $\mathrm{Mn}^{2+}$-containing NMOFs have shown excellent efficacy as $\mathrm{T}_{1}$-weighted contrast agents with large per metal- and per particle-based MR relaxivities. $\mathrm{Fe}^{3+}$ containing NMOFs have demonstrated excellent $\mathrm{T}_{2}$-weighted contrast enhancement. Upon intravenous injection of iron carboxylate NMOFs in Wistar rats, researchers observed negative

(C) 2011 American Chemical Society

*To whom correspondence should be addressed. wlin@unc.edu. 
signal enhancement in the liver and spleen, which dissipated over time, indicating the degradation and clearance of the NMOF. Through the incorporation of luminescent or high $\mathrm{Z}$ element building blocks, NMOFs have also served as viable contrast agents for optical imaging or X-ray computed tomography (CT) imaging. Incorporation of membrane impermeable dyes into NMOFs allowed for their uptake by cancer cells and for their controlled release as the framework decomposed.

NMOFs have been used to deliver anticancer drugs and other chemotherapeutics. Cisplatin prodrugs were incorporated within NMOFs at exceptionally high levels, either through use of the prodrug as the building block or through attachment of the prodrug onto the framework after synthesis. These NMOFs were encapsulated within a silica shell and targeted to cancer cells. In vitro assays revealed that the targeted NMOFs possessed similar efficacy to cisplatin, while the nontargeted NMOFs were less active. Several different therapeutic molecules were loaded within porous iron-carboxylate NMOFs at unprecedented levels. The NMOF showed sustained drug release with no burst effect, and in vitro assays revealed that the nanoencapsulated drug possessed similar efficacy to the free drug. Although still at a very early stage of development, NMOFs have already shown great promise as a novel platform for nanomedicine. The compositional tunability and mild synthetic conditions used to produce NMOFs should allow for the incorporation of other imaging and therapeutic agents and their effective delivery to targeted cells in vivo.

\section{Introduction}

Metal-organic frameworks (MOFs), also called coordination polymers or coordination networks, are a class of hybrid materials formed by the self-assembly of metal ions or clusters and polydentate bridging ligands typically under mild conditions. Due to virtually limitless combinations of metals and ligands, the physicochemical properties of MOFs can be judiciously tuned for specific applications. As a result, bulk phase MOFs have shown promise for a number of diverse applications including gas storage, ${ }^{1,2}$ catalysis, ${ }^{3-5}$ nonlinear optics, ${ }^{6}$ separations, ${ }^{7,8}$ sensing, ${ }^{9,10}$ and light-harvesting. ${ }^{11}$ Because MOFs can exhibit exceptionally high surface areas with large pore sizes, they have also been investigated for applications in loading and controlled release of several drug molecules. ${ }^{12-14}$ However, MOFs need to be scaled down to the nanoregime to form nanoscale metal-organic frameworks (NMOFs) for use as delivery vehicles for imaging agents and drug molecules. We and others have recently shown that NMOFs can be synthesized using a variety of different techniques that have been developed for inorganic and organic polymeric nanoparticles. NMOFs not only maintain the structural diversity and physicochemical properties as bulk MOFs but also exhibit particle dimensions in the tens to hundreds of nanometers range, making them potential nanocarriers for imaging agents and drug molecules. ${ }^{15-17}$

Although a large number of materials have been developed as nanocarriers for imaging and therapuetic agents, ${ }^{18-21}$ the majority of them can be categorized into either purely inorganic (such as quantum dots, $\mathrm{Fe}_{3} \mathrm{O}_{4}$, and Au nanoparticles) or purely organic (such as liposomes, dendrimers, polymers). Each of these classes of nanomaterials has its own strengths and weaknesses. NMOFs possess some potential advantages over existing nanocarriers. First, MOFs are compositionally and structurally diverse, allowing for the facile synthesis of NMOFs of different compositions, shapes, sizes, and chemical properties. Second, NMOFs are intrinsically biodegradable as a result of relatively labile metal-ligand bonds, making it possible to rapidly degrade and clear the nanocarriers after the intended task is completed. In this Account, we intend to summarize recent advances in the development of NMOFs as delivery vehicles for imaging agents and molecular therapeutics. More specialized reviews focusing on the synthesis of NMOFs ${ }^{15,16}$ and the use of NMOFs in biomedical imaging ${ }^{22}$ and in drug delivery ${ }^{23}$ have recently appeared. 


\section{Synthesis of Nanoscale Metal-Organic Frameworks}

As the synthesis of nanoscale and microscale MOFs has recently been reviewed, ${ }^{15,16}$ we only outline general synthetic strategies here with specific examples of the synthesis of biomedically relevant NMOFs. Four general methods have been utilized to synthesize NMOFs: nanoprecipitation, solvothermal, reverse microemulsion, and surfactant-templated solvothermal reactions. The first method tends to yield amorphous materials, while the latter three methods can afford crystalline materials, owing to the ability to exert a better control on nanoparticle nucleation and growth kinetics. The first two methods are surfactant-free, whereas the last two methods rely on surfactants not only to control the particle synthesis but also to stabilize these particles.

In a typical NMOF synthesis, precursor solutions are mixed together to allow particle nucleation and growth (Figure 1a). In the nanoprecipitation method, nanoparticles form because the particles are insoluble in the solvent system whereas the individual precursors remain soluble. This strategy was used to synthesize NMOFs composed of the anticancer prodrug $c, c, t-\mathrm{Pt}\left(\mathrm{NH}_{3}\right)_{2} \mathrm{Cl}_{2}$ (succinate) $)_{2}(\mathrm{DSCP})$ and $\mathrm{Tb}^{3+}(\mathbf{1}){ }^{24}$ In this synthesis, the $\mathrm{pH}$ value of an aqueous solution of $\mathrm{TbCl}_{3}$ and $\left[\mathrm{NMeH}_{3}\right]_{2} \mathrm{DSCP}$ was adjusted to 5.5 with aqueous sodium hydroxide. Methanol was then quickly added to the precursor solution, leading to the instantaneous formation of $\mathbf{1}$ which were shown by SEM and DLS to adopt a spherical morphology with a diameter of 50-60 nm (Figure 1b). 1 contains $75 \mathrm{wt} \%$ of the DSCP prodrug; such a high loading of cisplatin has not been achieved using other nanocarriers. ${ }^{26,27}$

Solvothermal synthesis of NMOFs can be achieved with either conventional heating or a microwave. Because high reaction temperatures are involved in the solvothermal method, more extensive transformations of the precursors typically occur before the formation of the NMOF nanoparticles. Temperatures and heating rates provide additional parameters to control the NMOF particle nucleation and growth. For example, $\mathrm{Fe}^{3+} \mathrm{NMOF}$ particles with the formula of $\mathrm{Fe}_{3}\left(\mu_{3}-\mathrm{O}\right) \mathrm{Cl}\left(\mathrm{H}_{2} \mathrm{O}\right)(\mathrm{BDC})_{3}(2)$ were synthesized by heating an equimolar solution of $\mathrm{FeCl}_{3}$ and terephthalic acid (BDC) with a microwave. ${ }^{25} \mathbf{2}$ displayed an octahedral morphology with an average diameter of $200 \mathrm{~nm}$ (Figure 1c). PXRD studies showed that $\mathbf{2}$ was highly crystalline and adopted the known MIL-101 structure. 2 could also be modified by incorporating a fraction of 2-aminoterephallic acid $\left(\mathrm{NH}_{2}-\mathrm{BDC}\right)$ to form $\mathbf{2 a}$ particles that provided an orthogonal amino group for further functionalization. 2a retained the MIL-101 structure with up to $17.5 \mathrm{~mol} \%$ of $\mathrm{NH}_{2}-\mathrm{BDC}$ incorporation, while the particles synthesized with higher amounts of $\mathrm{NH}_{2}-\mathrm{BDC}$ adopted the nonporous MIL-88B structure.

Surfactant-assisted synthesis of NMOFs can be carried out at room temperature or at elevated temperatures. Because the building blocks for NMOFs are typically water-soluble, reverse microemulsions provide another method to control the nucleation and growth kinetics of NMOF particles. Reverse microemulsions are formed by using surfactants to stabilize water droplets within a nonpolar organic phase (Figure 2a). This method was used to synthesize crystalline $\mathrm{Gd}(\mathrm{BDC})_{1.5}\left(\mathrm{H}_{2} \mathrm{O}\right)_{2}(\mathbf{3})$ nanorods (Figure $2 \mathrm{~b}$ ). ${ }^{28}$ Two separate microemulsions containing either $\mathrm{GdCl}_{3}$ or $\left[\mathrm{NMeH}_{3}\right]_{2}[\mathrm{BDC}]$ were mixed and allowed to react for a given amount of time. The particle morphologies could be controlled by adjusting the $w$ value (water to surfactant molar ratio) of the micro-emulsion. 3 synthesized at $w=10$ was $1-2 \mu \mathrm{m}$ in length and $100 \mathrm{~nm}$ in diameter. Nanorods of 100-125 $\mathrm{nm}$ in length and 40 $\mathrm{nm}$ in diameter were obtained when the $W$ value was decreased to $5 . \mathrm{Gd}(\mathrm{BTC})\left(\mathrm{H}_{2} \mathrm{O}\right)_{3}(\mathbf{4}$, BTC $=$ benzene-1,2,4-tricarboxylate) nanoplates of $\sim 100 \mathrm{~nm}$ in diameter and $\sim 35 \mathrm{~nm}$ in thickness were also synthesized by this method. Both $\mathbf{3}$ and $\mathbf{4}$ were crystalline and matched known lanthanide-carboxylate bulk phases. 
Surfactant molecules can also be used to template the NMOF synthesis under solvothermal conditions (Figure 2a) by coating the surfaces of growing NMOF particles. Surfactant molecules play an important role in defining NMOF morphologies. For example, Gd-BHC NMOFs (BHC = benzene hexacarboxylic acid) were synthesized by a surfactant templated solvothermal method. ${ }^{29}$ A reverse microemulsion of $\mathrm{GdCl}_{3}$ and $\left[\mathrm{NMeH}_{3}\right]_{6}[\mathrm{BHC}]$ was transferred to a Parr reactor and heated at $120^{\circ} \mathrm{C}$. The resulting NMOF had the formula $\mathrm{Gd}_{2}(\mathrm{BHC})\left(\mathrm{H}_{2} \mathrm{O}\right)_{6}(\mathbf{5})$ and exhibited a blocklike morphology with dimensions of $25 \times 50 \times$ $100 \mathrm{~nm}^{3}$ (Figure 2c). 5 was crystalline and matched a previously reported lanthanide-BHC phase. The compositions and morphologies of Gd-BHC NMOFs were also shown to be sensitive to the $\mathrm{pH}$ values of the reaction system. MOF microparticles of a different composition were obtained when the reaction was carried out at lower $\mathrm{pH} .{ }^{29}$

The four general methods described above have been adopted to synthesize a large number of NMOFs. With the ability to independently adjust NMOF precursors, reaction solvents, $\mathrm{pH}$ values, temperatures, surfactant or other templating molecules, $w$ values, and other parameters, a range of NMOFs with well-defined compositions and morphologies have been synthesized. It has also been shown that surface termination can be an important parameter in defining NMOF morphologies. ${ }^{30,31}$ Although the synthesis of NMOFs has been phenomenologically described, there is little study on the NMOF growth mechanism and kinetics. Fundamental understanding of NMOF growth mechanism and kinetics will facilitate the development of NMOFs as a promising class of hybrid nanomaterials for biological and biomedical applications.

\section{Strategies to Incorporate Biomedically Relevant Agents within NMOFs}

Several different methods have been developed to incorporate imaging and therapeutic agents into NMOFs by taking advantage of the tailorability of NMOFs to afford very high agent loadings. These loading methods fall into two general categories: direct incorporation during NMOF synthesis or postsynthesis loading (Figure 3). A combination of these two strategies can also be used to load different agents into NMOFs to allow the development of multimodal imaging agents or theranostic nanoparticles.

In the direct incorporation strategy, biomedically relevant agents are used as either the metal connecting points ${ }^{28-30,32}$ or the bridging ligand to assemble NMOFs (Figure 3a). ${ }^{24,33,34}$ Paramagnetic metal ions such as $\mathrm{Gd}^{3+}, \mathrm{Fe}^{3+}$, and $\mathrm{Mn}^{2+}$ not only link the ligands to form the NMOFs but also act as magnetic resonance imaging (MRI) contrast enhancement agents either in intact NMOF particles or upon dissolution of NMOF particles (Table 1). DSCP and $\mathrm{I}_{4}-\mathrm{BDC}$ were used to bridge metal centers to form NMOFs to provide the anticancer therapeutic cisplatin or the high $\mathrm{Z}$ element iodine for CT imaging, respectively. ${ }^{24,33}$ The direct incorporation strategy has the ability to achieve very high agent loadings with uniform distribution throughout the nanoparticle, but the morphology and physicochemical properties of these NMOFs need to be individually tuned. Care must also be taken to ensure that the agent is not altered or degraded during the NMOF synthesis. The direct incorporation strategy can be modified to include a small amount of the biomedically relevant agent during the synthesis as a dopant, imparting additional functionality to the NMOF (Table 1). This method has been used to encapsulate a number of different agents with various properties such as optical dyes, chemotherapeutics, proteins, and smaller nanoparticles. ${ }^{35-41}$ However, only a low drug loading can be achieved by this method and the release kinetics of the agent from the NMOF may be very different than the framework decomposition rate.

In the postsynthesis loading strategy, biomedically relevant agents are loaded into the NMOF pores. After the synthesis of highly porous NMOFs, the active agent is incorporated 
within the NMOF by noncovalent (Figure 3b1) or covalent interactions (Figure 3b2). Noncovalent drug loading was first demonstrated using bulk phase MOFs, ${ }^{12-14}$ achieving impressive loading of up to $1.4 \mathrm{~g}$ of ibuprofen/g of MOF. ${ }^{12}$ Release studies showed very slow, sustained drug release from the framework with minimal burst effects. More recent studies have extended this strategy to NMOFs which have been loaded with hydrophilic, amphiphillic, and hydrophobic drugs. ${ }^{30}$ The NMOF pore size must be larger than the encapsulated agent to afford high loadings.

Since noncovalent drug loading is an inherently reversible process, subsequent processing of the NMOF may lead to premature release of the agent. Postsynthesis covalent attachment of the agent offers a more robust approach, as the agent will only be released when the NMOF decomposes. In this method, orthogonal functional groups within the frameworks of porous NMOFs are used to covalently attach active agents. ${ }^{25,42}$ This strategy effectively creates a prodrug, so it is essential that the functionality of the agent is maintained. The active drug must be cleavable from the NMOF under specific biological conditions. As functional groups at or near the surface of the nanoparticle are kinetically more accessible, agent loading might not be uniform throughout the NMOF particles. As an example, NMOF 2a possessed $\mathrm{NH}_{2}-\mathrm{BDC}$ groups, which were used to attach either an optical contrast agent or a chemotherapeutic through covalent bonds. ${ }^{25}$

\section{Surface Modification of NMOFs}

As-synthesized nanomaterials typically need to be further functionalized to optimize their in vivo performance. Surface modification is a commonly used strategy for improving water dispersity, reducing plasma protein binding, avoiding the reticuloendothelial system, and adding affinity molecules to target specific cells or tissues. ${ }^{43}$ Surface modification is particularly important for NMOFs because of the intrinsic instability of many NMOFs under physiological conditions; surface coatings can slow down the degradation of NMOFs and thus prevent premature release of cargoes. Two general strategies have been used to modify the NMOF surfaces: silica encapsulation and coating with organic polymers (Figure 4). Other surface functionalization approaches need to be explored to further optimize the in vivo performance of many NMOFs.

Lin and co-workers first stabilized NMOFs by encapsulating them within a silica shell. Silica coatings have been extensively used to modify inorganic and polymer nanoparticles. ${ }^{4,45} \mathrm{~A}$ silica shell offers several advantages as a surface coating, including biocompatibility, increased water dispersibility, and easy functionalization with silyl-derived molecules. Generally, NMOFs are first coated with a hydrophilic polymer, such as polyvinylpyrrolidone (PVP), to keep the NMOF particles well dispersed so that individual NMOF particles (but not aggregates) are coated with silica shells. For example, NMOF 3 was first coated with PVP and then treated with tetraethylorthosilicate (TEOS) in basic ethanol to afford $3 @$ silica core-shell nanostrcutures. ${ }^{46}$ The silica shell thickness can be controlled by adjusting the reaction time or reactant concentrations. Release profile experiments demonstrated that a silica shell significantly slows down the rate of NMOF dissolution and $\mathrm{Gd}$ release, and the kinetics of $\mathrm{Gd}^{3+}$ release depends on the silica shell thickness. This method was also used to coat $\mathrm{Tb}^{3+}$ - and $\mathrm{Mn}^{2+}$-carboxylate NMOFs. ${ }^{24,32} \mathbf{2 a}$ was coated with silica by an alternative method using sodium silicate as the silica source as iron-carboxylate NMOFs are unstable under basic conditions. ${ }^{25}$ The surface of these coreshell NMOFs can be further modified by grafting a silyl-derived molecule onto the silica shell through surface silanol groups to impart additional functionality. ${ }^{24,25,32,46}$ For example, RGD-targeted $\mathbf{1}$ increased its anticancer efficacy against human colon cancer cells compared to the untargeted $1 .{ }^{24}$ 
Subsequent studies have modified the surface of NMOFs with organic polymers (Figure 4) as a way to enhance biocompatibility and retard framework decomposition. ${ }^{30,47-49}$ The polymers must possess an end group that can bind to the NMOF through either vacant metal coordination sites, electrostatic attraction to the particle surface, or covalent attachment to the bridging ligand. Polymers can be added either during NMOF synthesis or postsynthetically. A number of different polymers were conjugated to 3 through the thiol end groups of the polymers which bind to vacant $\mathrm{Gd}^{3+}$ coordination sites. ${ }^{47,48}$ The polymer coatings slow down the release of $\mathrm{Gd}^{3+}$ ions. Additional functional groups on the polymer allowed for the incorporation of chemotherapeutics, optical imaging agents, and targeting agents. Polymer modification also altered the properties of $\mathbf{3}$ as a MRI contrast agent. Lin and co-workers modified the surface of several NMOFs with PVP to stabilize the NMOF and increase its dispersibility as a way to increase the efficiency of a subsequent silica coating step. ${ }^{24,32,46}$ As a large inventory of polymers are available for biomedical applications, surface modification with polymers imparts additional tunability to optimize the performance of polymer coated NMOFs.

\section{Biomedical Applications of NMOFs}

\section{Magnetic Resonance Imaging}

Magnetic resonance imaging (MRI) is a noninvasive imaging technique based on the detection of nuclear spin reorientations in a magnetic field. MRI provides excellent spatial resolution, high soft tissue contrast, and large penetration depth. However, MRI is intrinsically insensitive and generally used for the detection of water protons which are present in high molar concentrations in biological specimens. ${ }^{50}$ Large doses of contrast enhancement agents, typically small-molecule Gd chelates, are used in approximately 35\% of all clinical scans to enhance the contrast between normal and diseased tissues. ${ }^{51} \mathrm{Gd}$ chelates provide $\mathrm{T}_{1}$-weighted, or positive, signal enhancement. Superparamagnetic materials such iron oxide nanoparticles are clinically used for $\mathrm{T}_{2}$-weighted or negative signal enhancement. ${ }^{52}$ The effectiveness of a MRI contrast agent is expressed by the relaxivity value ( $r_{1}$ for positive enhancement and $r_{2}$ for negative enhancement), with agents possessing large relaxivities providing more effective contrast.

The effectiveness of $\mathrm{Gd}^{3+}$-containing NMOFs as $\mathrm{T}_{1}$-weighted contrast agents was first demonstrated by Lin and co-workers who showed that $\mathbf{3}$ and $\mathbf{4}$ possessed $\mathrm{r}_{1}$ values about an order of magnitude higher than that of Omniscan, a clinically used small molecule contrast agent, at 3T (Figure 5, Table 2). ${ }^{28}$ A number of other studies have been published since, supporting the finding that $\mathrm{Gd}^{3+}$-containing NMOFs can exhibit extraordinarily high MR relaxivities. ${ }^{28,29,39,47,48,53,54}$ Many of the $\mathrm{Gd}^{3+}$-containing NMOFs could also act as $\mathrm{T}_{2^{-}}$ weighted contrast agents, which is not possible using small molecule Gd chelates (Figure 5 and Table 2). As previously mentioned, the size and aspect ratio of $\mathbf{3}$ could be manipulated by changing the $W$ value of the microemulsion. The relaxivity values of the nanoparticles showed an inverse dependence on nanoparticle size, with the smaller nanoparticles possessing larger $r_{1}$ relaxivity. It was believed that smaller nanoparticles have higher surface to volume ratios, which enhanced the exchange between $\mathrm{Gd}^{3+}$ bound water and bulk water, leading to higher relaxivities. This size dependent trend on relaxivity was also observed in $\mathrm{Gd}^{3+}$-containing NMOFs synthesized by Kimizuka and co-workers. ${ }^{39}$ Boyes and co-workers were able to tune the relaxivity of $\mathbf{3}$ by polymer surface modification. ${ }^{47,48}$ Hydrophilic polymers led to an increased $r_{1}$ relaxivity, while hydrophobic polymers increased the $r_{2}$ relaxivity compared to the unmodified nanoparticle. The differences in relaxivities were explained by increased or decreased polymer water retention.

As the toxicity of $\mathrm{Gd}^{3+}$ ions is now well established, ${ }^{55}$ the in vivo utility of $\mathrm{Gd}^{3+}$-containing NMOFs is uncertain. Lin and co-workers have developed Mn-based NMOFs for $\mathrm{T}_{1^{-}}$ 
weighted contrast enhancement. ${ }^{32} \mathrm{Mn}^{2+}$ ions have been shown to be potent MRI contrast agents with lower toxicity than free $\mathrm{Gd}^{3+.56,57}$ Reaction of $\mathrm{Mn}^{2+}$ with BDC led to nanorods of $\mathrm{Mn}(\mathrm{BDC})\left(\mathrm{H}_{2} \mathrm{O}\right)_{2}(\mathbf{6})$, which were $50-100 \mathrm{~nm}$ in diameter and up to several micrometers in length. Blocklike nanoparticles of $\mathrm{Mn}_{3}\left({ }^{i} \mathrm{BTC}\right)_{2}\left(\mathrm{H}_{2} \mathrm{O}\right)_{6}\left(\mathbf{7},{ }^{i} \mathrm{BTC}=1,3,5\right.$-benzenetricarboxylic acid) of 50-300 nm in diameter were obtained when ${ }^{i} \mathrm{BTC}$ was used in place of BDC. The NMOFs showed modest $r_{1}$ relaxivity (Table 2), but acted as reservoirs to selectively release large doses of $\mathrm{Mn}^{2+}$ ions to achieve $\mathrm{T}_{1}$-weighted signal enhancement. 7 was coated with a thin silica shell and functionalized with a cancer targeting peptide. MRI demonstrated increased uptake of the targeted nanoparticle, which was confirmed by confocal microscopy and ICP-MS studies (Figure 6). 7 was evaluated in vivo and demonstrated $\mathrm{T}_{1}$-weighted signal enhancement in the liver, spleen, and aorta $1 \mathrm{~h}$ after injection. This signal enhancement was believed to result from the $\mathrm{Mn}^{2+}$ ions released from the NMOF.

Horcajada and co-workers synthesized a series of iron-carboxylate NMOFs as $\mathrm{T}_{2}$-weighted contrast agents. ${ }^{30}$ These crystalline NMOFs ranged in size from 50 to $350 \mathrm{~nm}$, matching known bulk phase materials of MIL-89 (8), MIL-88A (9), MIL-100(10), MIL-101-NH ${ }_{2}$ (11), MIL-88Bt (12), and MIL-53 (13). Pegylated versions of 9 (PEG-9) and 10 (PEG-10) were also synthesized. 9, PEG-9, 10, and PEG-10 showed high $\mathrm{r}_{2}$ relaxivity (Table 2) on a per metal basis. 9 was evaluated in Wistar rats (Figure 7). Negative enhancement of the liver and spleen was observed after injection of $\mathbf{9}$, which dissipated 3 months postinjection, indicating the accumulation, degradation, and clearance of $\mathbf{9}$. Iron oxide nanoparticles have also been encapsulated within other NMOFs as guest species. ${ }^{35,58}$

\section{Optical Imaging}

Optical imaging is widely used in biological studies. Typically visible light is used to excite dye molecules within a tissue, which fluoresce at longer wavelengths. This technique is ubiquitous for in vitro and ex vivo studies but is limited by poor tissue penetration in in vivo applications. ${ }^{59}$ A number of NMOFs have been synthesized which are inherently luminescent, but have not been evaluated as biomedical imaging agents. ${ }^{28,29,39,60-63}$ The luminescence of these NMOFs is not ideal for biomedical imaging applications due to its nonoptimum absorption properties and low quantum yields. Lin and co-workers were able to create NMOFs containing a phosphorescent $\mathrm{Ru}(\mathrm{bpy}) 3^{2+}$ derivative as the bridging ligand and $\mathrm{Zn}^{2+}(\mathbf{1 4})$ or $\mathrm{Zr}^{4+}(\mathbf{1 5})$ metal connecting points (Figure 8). ${ }^{64} 15$ was coated with a layer of amorphous silica, functionalized with PEG, and targeted to cancer cells. Confocal microscopy studies using human lung cancer cells demonstrated increased uptake of the targeted nanoparticles (Figure 8), which was confirmed by ICP-MS analysis.

In some cases, the optical dye was incorporated within the framework either postsynthetically or as a guest species. ${ }^{25,35,37,39-41,60}$ For example, silica coated 7 was modified with both a fluororophore and targeting peptide. ${ }^{32}$ Confocal microscopy showed increased uptake of the targeted particle by cancer cells, confirming the MR imaging results (Figure 6b-d). Lin and co-workers functionalized 2a with a Bodipy-based fluorophore (Bodipy-2a) at 5.6-11.7 wt \% loadings. ${ }^{25}$ Intact Bodipy-2a was not fluorescent due to iron quenching, but it exhibited strong fluorescence upon NMOF decomposition. Confocal microscopy of silica coated Bodipy-2a showed dose dependent cellular localization and fluorescence. Boyes and co-workers modified the surface of $\mathbf{3}$ with a PNIPAM-co-PNAOSco-PFMA copolymer (3a). ${ }^{48}$ This polymer contained fluorescein and a succinimide group for further functionalization. 3a was targeted to cancer cells and its uptake in canine FITZHSA cells was investigated by fluorescence microscopy. The targeted nanoparticle showed cellular localization after $1 \mathrm{~h}$ of incubation and cellular internalization after $24 \mathrm{~h}$, while untargeted 3a did not show any localization or uptake. Kimizuka and co-workers created a 
series of NMOFs based on lanthanide ions and nucleotides. ${ }^{37-39,60,65}$ Anionic dyes, such as perylene-3,4,9,10-tertacarboxylate, were incorporated within NMOFs of adenosine $5^{\prime}$ monophosphate and $\mathrm{Gd}^{3+}$ (perylene-16). Confocal microscopy showed the uptake of perylene-16 into the lysosomes of HeLa cells and its biodistribution was studied in a murine model. Ex vivo analysis showed that perylene-16 accumulated and remained in the liver for up to $48 \mathrm{~h}$ post-injection, with no fluorescence observed in the kidneys, lungs, or spleen. Lanthanide-nucleotide NMOFs were used to successfully encapsulate other anionic dyes and negatively charged quantum dots as well. ${ }^{37-39}$

\section{X-ray Computed Tomography (CT) Imaging}

$\mathrm{CT}$ imaging is based on specimen attenuation of $\mathrm{X}$-rays and can provide 3D images with excellent spatial resolution. ${ }^{66,67}$ High $\mathrm{Z}$ number elements such as iodine, barium, and bismuth are typically used as CT contrast agents; however, they must be administered in large doses (tens of grams) to achieve adequate contrast. A nanoparticle platform can thus provide superior contrast enhancement. Lin and co-workers constructed NMOFs containing $\mathrm{I}_{4}-\mathrm{BDC}$ and either $\mathrm{Cu}^{2+}(\mathbf{1 7})$ or $\mathrm{Zn}^{2+}(\mathbf{1 8}){ }^{33} \mathrm{CT}$ phantom studies showed that both nanoparticles possessed slightly higher X-ray attenuation factors than iodixanol, a commercially used contrast agent (Figure 9). The higher nanoparticle attenuation results from the contributions of the metal centers. NMOFs should provide an interesting platform for incorporating other high Z elements for CT imaging.

\section{Drug Delivery}

Current small molecule drugs are often limited by their nonspecific distribution throughout the body, leading to high doses, rapid clearance, poor pharmacokinetics, and high side effects. Many of these drawbacks can be alleviated through the use of nanoparticulate formulations. Nanoparticles often possess superior pharmacokinetic profiles, so incorporating a drug within a nanoparticle can lead to improved efficacy. The clinical success of nanoparticle therapeutics such as Doxil and Abraxane illustrate the power of this approach, and many other nanoparticle-based therapeutics have shown promise in clinical trials. ${ }^{18}$ Lin and co-workers have developed two NMOF platforms to deliver cisplatin-based chemotherapeutics. ${ }^{24,25}$ NMOF-1 was built from a cisplatin prodrug DSCP and $\mathrm{Tb}^{3+}$ ions using a nanoprecipitation procedure. $\mathbf{1}$ was coated with a thin layer of silica (1a) and targeted with a silyl-derived peptide (1b) to cancer cells. When $\mathbf{1 a}$ is placed in physiological medium, the framework decomposes and the cisplatin prodrug diffuses through the silica shell in a controlled manner (Figure 10a). 1b possessed similar cytotoxicity against human colon cancer cells as cisplatin, while $\mathbf{1}$ and $\mathbf{1 a}$ were less effective, presumably due to increased uptake of $\mathbf{1 b}$ via receptor mediated endocytosis. Iron(III)-carboxylate NMOF 2a was also postsynthetically modified to contain a cisplatin prodrug, $c, c, t-$

$\mathrm{Pt}\left(\mathrm{NH}_{3}\right)_{2} \mathrm{Cl}_{2}$ (succinate)(OEt) (cisplatin-2a, Figure 10b). ${ }^{25}$ Silica-coated cisplatin-2a with a RGD peptide targeting ligand demonstrated comparable cytotoxicity to cisplatin in vitro. 3a could also be modified to contain methotrexate, which showed similar cytotoxicity against FITZ-HSA cells to the free methotrexate. ${ }^{48}$

Horcajada and co-workers encapsulated a number of therapeutics within the ironcarboxylate NMOFs 8-11 and 13. ${ }^{30}$ These synthesized NMOFs were soaked in drug solutions for loading. The anticancer drug busulfan could be loaded into 9 at 5 times the loading of previously reported systems. In vitro cytotoxicity assays showed that busulfanloaded $\mathbf{9}$ possessed the same activity as the free drug against several cell lines. 9 was also loaded with triphosphorylated azidothymidine, an anti-HIV drug. In vitro assays showed that loaded 9 possessed significant anti-HIV activity. Maspoch and co-workers encapsulated several anticancer drugs as guest species within NMOFs synthesized from $\mathrm{Zn}^{2+}$ and 1,4bis(imidazol-1-ylmethyl)benzene (19). ${ }^{36}$ These drugs were encapsulated within 19 with 
modest efficiency $(\approx 20 \mathrm{wt} \%)$ and showed fast drug release. In vitro assays performed with doxorubicin-loaded 19 showed comparable cytotoxicity to that of free doxorubicin. Iron carboxylate NMOFs such as $\mathbf{2 a}, \mathbf{3 a}$, and $\mathbf{8 - 1 3}$ possess considerable potential to act as theranostic agents, as these NMOFs were utilized as both imaging contrast and drug delivery agents; ${ }^{25,30}$ further work is needed to demonstrate the real-time monitoring of drug uptake and treatment efficacy.

\section{Conclusions and Future Outlook}

The development of NMOFs as biomedical imaging and drug delivery agents is in its infancy when compared to other nanocarriers. Nonetheless, NMOFs have already shown great promise as a new nanocarrier platform owing to the structural and chemical diversity, mild synthetic conditions, and the ability to carry a diverse array of imaging and therapeutic agents in unprecedentedly high loadings. We foresee that many other imaging agents and drugs will be incorporated into NMOFs in the future by taking advantage of the totally tunable nature of NMOFs. Particularly, combining both imaging and therapeutic agents in the same NMOF platform should greatly facilitate the efficacy studies of this promising class of theranostic nanoparticles. NMOFs also need to be further refined by using biocompatible components and by achieving more effective surface functionalization to ensure prolonged blood circulation, evasion of the RES system, and better tissue specificity. Although there have been considerable amounts of in vitro efficacy studies on NMOFs, no systematic investigation of in vivo efficacy has been launched yet. Such systematic in vivo studies are needed in order to optimize the performance of NMOFs. Optimized NMOFs should have a bright future in biomedical imaging and drug delivery.

\section{Acknowledgments}

We thank the National Cancer Institute (U01-CA151455 and U54-151652) and the National Science Foundation (DMR-0906662) for financial support.

\section{References}

1. Dinca M, Long JR. Hydrogen storage in microporous metal-organic frameworks with exposed metal sites. Angew Chem, Int Ed. 2008; 47:6766-6779.

2. Rowsell JLC, Yaghi OM. Strategies for hydrogen storage in metal-organic frameworks. Angew Chem, Int Ed. 2005; 44:4670-4679.

3. Lee J, Farha OK, Roberts J, Scheidt KA, Nguyen ST, Hupp JT. Metal-organic framework materials as catalysts. Chem Soc Rev. 2009; 38:1450-1459. [PubMed: 19384447]

4. Ma LQ, Abney C, Lin WB. Enantioselective catalysis with homochiral metal-organic frameworks. Chem Soc Rev. 2009; 38:1248-1256. [PubMed: 19384436]

5. Ma LQ, Falkowski JM, Abney C, Lin WB. A series of isoreticular chiral metal-organic frameworks as a tunable platform for asymmetric catalysis. Nat Chem. 2010; 2:838-846. [PubMed: 20861899]

6. Evans OR, Lin WB. Crystal engineering of NLO materials based on metal-organic coordination networks. Acc Chem Res. 2002; 35:511-522. [PubMed: 12118990]

7. Liu Y, Xuan WM, Cui Y. Engineering Homochiral Metal-Organic Frameworks for Heterogeneous Asymmetric Catalysis and Enantioselective Separation. Adv Mater. 2010; 22:4112-4135. [PubMed: 20799372]

8. Li JR, Kuppler RJ, Zhou HC. Selective gas adsorption and separation in metal-organic frameworks. Chem Soc Rev. 2009; 38:1477-1504. [PubMed: 19384449]

9. Xie ZG, Ma LQ, deKrafft KE, Jin A, Lin WB. Porous Phosphorescent Coordination Polymers for Oxygen Sensing. J Am Chem Soc. 2010; 132:922-923. [PubMed: 20041656]

10. Chen BL, Xiang SC, Qian GD. Metal-Organic Frameworks with Functional Pores for Recognition of Small Molecules. Acc Chem Res. 2010; 43:1115-1124. [PubMed: 20450174] 
11. Kent CA, Mehl BP, Ma L, Papanikolas JM, Meyer TJ, Lin W. Energy Transfer Dynamics in Metal-Organic Frameworks. J Am Chem Soc. 2010; 132:12767-12769. [PubMed: 20735124]

12. Horcajada P, Serre C, Vallet-Regi M, Sebban M, Taulelle F, Ferey G. Metal-organic frameworks as efficient materials for drug delivery. Angew Chem, Int Ed. 2006; 45:5974-5978.

13. Horcajada P, Serre C, Maurin G, Ramsahye NA, Balas F, Vallet-Regi M, Sebban M, Taulelle F, Ferey G. Flexible porous metal-organic frameworks for a controlled drug delivery. J Am Chem Soc. 2008; 130:6774-6780. [PubMed: 18454528]

14. An JY, Geib SJ, Rosi NL. Cation-Triggered Drug Release from a Porous Zinc-Adeninate MetalOrganic Framework. J Am Chem Soc. 2009; 131:8376-8377. [PubMed: 19489551]

15. Lin W, Rieter WJ, Taylor KML. Modular Synthesis of Functional Nanoscale Coordination Polymers. Angew Chem, Int Ed. 2009; 48:650-658.

16. Spokoyny AM, Kim D, Sumrein A, Mirkin CA. Infinite coordination polymer nano- and microparticle structures. Chem Soc Rev. 2009; 38:1218-1227. [PubMed: 19384433]

17. Catala L, Volatron F, Brinzei D, Mallah T. Functional Coordination Nanoparticles. Inorg Chem. 2009; 48:3360-3370. [PubMed: 19361238]

18. Davis ME, Chen Z, Shin DM. Nanoparticle therapeutics: an emerging treatment modality for cancer. Nat Rev Drug Discovery. 2008; 7:771-782.

19. De Jong WH, Borm PJA. Drug delivery and nanoparticles: Applications and hazards. Int J Nanomed. 2008; 3:133-149.

20. Peer D, Karp JM, Hong S, Farokhzad OC, Margalit R, Langer R. Nanocarriers as an emerging platform for cancer therapy. Nat Nanotechnol. 2007; 2:751-760. [PubMed: 18654426]

21. Taylor-Pashow KML, Della Rocca J, Huxford RC, Lin WB. Hybrid nanomaterials for biomedical applications. Chem Commun. 2010; 46:5832-5849.

22. Della Rocca J, Lin WB. Nanoscale Metal-Organic Frameworks: Magnetic Resonance Imaging Contrast Agents and Beyond. Eur J Inorg Chem. 2010:3725-3734.

23. Huxford RC, Della Rocca J, Lin W. Metal-organic frameworks as potential drug carriers. Curr Opin Chem Biol. 2010; 14:262-268. [PubMed: 20071210]

24. Rieter WJ, Pott KM, Taylor KML, Lin W. Nanoscale coordination polymers for platinum-based anticancer drug delivery. J Am Chem Soc. 2008; 130:11584-11585. [PubMed: 18686947]

25. Taylor-Pashow KML, Della Rocca J, Xie Z, Tran S, Lin W. Postsynthetic modifications of ironcarboxylate nanoscale metal-organic frameworks for imaging and drug delivery. J Am Chem Soc. 2009; 131:14261-14263. [PubMed: 19807179]

26. Haxton KJ, Burt HM. Polymeric Drug Delivery of Platinum-Based Anticancer Agents. J Pharm Sci. 2008; 98:2299-2316. [PubMed: 19009590]

27. Sathopoulos GP. Liposomal Cisplatin: A New Cisplatin Formulation. Anticancer Drugs. 2010; 21:732-736. [PubMed: 20671511]

28. Rieter WJ, Taylor KML, An H, Lin W, Lin W. Nanoscale metal-organic frameworks as potential multimodal contrast enhancing agents. J Am Chem Soc. 2006; 128:9024-9025. [PubMed: 16834362]

29. Taylor KML, Jin A, Lin W. Surfactant-assisted synthesis of nanoscale gadolinium metal-organic frameworks for potential multimodal imaging. Angew Chem, Int Ed. 2008; 47:7722-7725.

30. Horcajada P, Chalati T, Serre C, Gillet B, Sebrie C, Baati T, Eubank JF, Heurtaux D, Clayette P, Kreuz C, Chang JS, Hwang YK, Marsaud V, Bories PN, Cynober L, Gil S, Ferey G, Couvreur P, Gref R. Porous Metal-Organic-Framework Nanoscale Carriers as a Potential Platform for Drug Delivery and Imaging. Nat Mater. 2010; 9:172-178. [PubMed: 20010827]

31. Tanaka D, Kitagawa S. Template Effects in Porous Coordination Polymers. Chem Mater. 2008; 20:922-931.

32. Taylor KML, Rieter WJ, Lin W. Manganese-based nanoscale metal-organic frameworks for magnetic resonance imaging. J Am Chem Soc. 2008; 130:14358-14359. [PubMed: 18844356]

33. deKrafft KE, Xie ZG, Cao GH, Tran S, Ma LQ, Zhou OZ, Lin WB. Iodinated Nanoscale Coordination Polymers as Potential Contrast Agents for Computed Tomography. Angew Chem, Int Ed. 2009; 48:9901-9904. 
34. Miller SR, Heurtaux D, Baati T, Horcajada P, Greneche JM, Serre C. Biodegradable therapeutic MOFs for the delivery of bioactive molecules. Chem Commun. 2010; 46:4526-4528.

35. Imaz I, Hernando J, Ruiz-Molina D, Maspoch D. Metal-Organic Spheres as Functional Systems for Guest Encapsulation. Angew Chem, Int Ed. 2009; 48:2325-2329.

36. Imaz I, Rubio-Martinez M, Garcia-Fernandez L, Garcia F, Ruiz-Molina D, Hernando J, Puntes V, Maspoch D. Coordination polymer particles as potential drug delivery systems. Chem Commun. 2010; 46:4737-4739.

37. Nishiyabu R, Aime C, Gondo R, Kaneko K, Kimizuka N. Selective inclusion of anionic quantum dots in coordination network shells of nucleotides and lanthanide ions. Chem Commun. 2010; 46:4333-4335.

38. Nishiyabu R, Aime C, Gondo R, Noguchi T, Kimizuka N. Confining Molecules within Aqueous Coordination Nanoparticles by Adaptive Molecular Self-Assembly. Angew Chem, Int Ed. 2009; 48:9465-9468.

39. Nishiyabu R, Hashimoto N, Cho T, Watanabe K, Yasunaga T, Endo A, Kaneko K, Niidome T, Murata M, Adachi C, Katayama Y, Hashizume M, Kimizuka N. Nanoparticles of Adaptive Supramolecular Networks Self-Assembled from Nucleotides and Lanthanide Ions. J Am Chem Soc. 2009; 131:2151-2158. [PubMed: 19166341]

40. Roming M, Lunsdorf H, Dittmar KEJ, Feldmann C. ZrO(HPO4) $)_{-\mathrm{x}}(\mathrm{FMN})_{\mathrm{X}}$ : Quick and Easy Synthesis of a Nanoscale Luminescent Biomarker. Angew Chem, Int Ed. 2010; 49:632-637.

41. Yan XH, Zhu PL, Fei JB, Li JB. Self-Assembly of Peptide-Inorganic Hybrid Spheres for Adaptive Encapsulation of Guests. Adv Mater. 2010; 22:1283-1284. [PubMed: 20437520]

42. Nguyen JG, Tanabe KK, Cohen SM. Postsynthetic diazeniumdiolate formation and NO release from MOFs. CrystEngComm. 2010; 12:2335-2338.

43. Li SD, Huang L. Pharmacokietics and biodistribution of nanoparticles. Mol Pharmacuetics. 2008; 5:496-504.

44. Zou H, Wu SS, Shen J. Polymer/silica nanocomposites: Preparation, characterization, properties, and applications. Chem Rev. 2008; 108:3893-3957. [PubMed: 18720998]

45. Liu SH, Han MY. Silica-Coated Metal Nanoparticles. Chem Asian J. 2010; 5:36-45. [PubMed: 19768718]

46. Rieter WJ, Taylor KML, Lin WB. Surface modification and functionalization of nanoscale metalorganic frameworks for controlled release and luminescence sensing. J Am Chem Soc. 2007; 129:9852-9853. [PubMed: 17645339]

47. Rowe MD, Chang CC, Thamm DH, Kraft SL, Harmon JF, Vogt AP, Sumerlin BS, Boyes SG. Tuning the Magnetic Resonance Imaging Properties of Positive Contrast Agent Nanoparticles by Surface Modification with RAFT Polymers. Langmuir. 2009; 25:9487-9499. [PubMed: 19422256]

48. Rowe MD, Thamm DH, Kraft SL, Boyes SG. Polymer-Modified Gadolinium Metal-Organic Framework Nanoparticles Used as Multifunctional Nanomedicines for the Targeted Imaging and Treatment of Cancer. Biomacromolecules. 2009; 10:983-993. [PubMed: 19290624]

49. Zhao D, Tan S, Yuan D, Lu W, Rezenom YH, Jiang H, Wang LQ, Zhou HC. Surface Functionalization of Porous Coordination Nanocages via Click Chemistry and Their Application in Drug Delivery. Adv Mater. 2011; 23:90-93. [PubMed: 20972982]

50. Hashemi, RH.; Bradley, WG, Jr. MRI The Basics. Williams and Wilkins; Baltimore: 1997.

51. Caravan P, Ellison JJ, McMurry TJ, Lauffer RB. Gadolinium (II) chelates as MRI contrast agents: structure dynamics and applications. Chem Rev. 1999; 99:2293-2352. [PubMed: 11749483]

52. Na HB, Song IC, Hyeon T. Inorganic Nanoparticles for MRI Contrast Agents. Adv Mater. 2009; 21:2133-2148.

53. Guari Y, Larionova J, Corti M, Lascialfari A, Marinone M, Poletti G, Molvinger K, Guerin C. Cyano-bridged coordination polymer nanoparticles with high nuclear relaxivity: toward new contrast agents for MRI. Dalton Trans. 2008:3658-3660. [PubMed: 18615211]

54. Larionova J, Guari Y, Sangregorio C, Guerina C. Cyano-bridged coordination polymer nanoparticles. New J Chem. 2009; 33:1177-1190. 
55. Broome DR, Girguis MS, Baron PW, Cottrell AC, Kjellin I, Kirk GA. Gadodiamide-associated nephrogenic systemic fibrosis: Why radiologists should be concerned. Am J Roentgenol. 2007; 188:586-592. [PubMed: 17242272]

56. Thunus L, Lejeune R. Overview of transition metal and lanthanide complexes as diagnostic tools. Coord Chem Rev. 1999; 184:125-155.

57. Lee JH, Koretsky AP. Manganese enhanced magnetic resonance imaging. Curr Pharm Biotechnol. 2004; 5:529-537. [PubMed: 15579042]

58. Kim SB, Cai C, Sun S, Sweigart DA. Incorporation of $\mathrm{Fe}_{3} \mathrm{O}_{4}$ Nanoparticles into Organometallic Coordination Polymers by Nanoparticle Surface Modification. Angew Chem, Int Ed. 2009; 48:2907-2910.

59. Wessels JT, Yamauchi K, Hoffman RM, Wouters FS. Advances in cellular, subcellular and nanoscale imaging in vitro and in vivo. Cytometry, Part A. 2010; 77:667-676.

60. Aime C, Nishiyahu R, Gondo R, Kimizuka N. Switching On Luminescence in Nucleotide/ Lanthanide Coordination Nanoparticles via Synergistic Interactions with a Cofactor Ligand. Chem, Eur J. 2010; 16:3604-3607. [PubMed: 20191631]

61. Kerbellec N, Catala L, Daiguebonne C, Gloter A, Stephan O, Bunzli JC, Guillou O, Mallah T. Luminescent coordination nanoparticles. New J Chem. 2008; 32:584-587.

62. Lee HJ, Cho W, Oh M. Fluorescent octahedron and rounded-octahedron coordination polymer particles (CPPs). CrystEngComm. 2010; 12:3959-3963.

63. Zhang XJ, Ballem MA, Ahren M, Suska A, Bergman P, Uvdal K. Nanoscale Ln(III)-Carboxylate Coordination Polymers ( $\mathrm{Ln}=\mathrm{Gd}, \mathrm{Eu}, \mathrm{Yb})$ : Temperature-Controlled Guest Encapsulation and Light Harvesting. J Am Chem Soc. 2010; 132:10391-10397. [PubMed: 20614891]

64. Liu D, Huxford RC, Lin W. Phosphorescent Nanoscale Coordination Polymers as Contrast Agents for Optical Imaging. Angew Chem, Int Ed. 2011; 50:3696-3700.

65. Aime C, Nishiyabu R, Gondo R, Kaneko K, Kimizuka N. Controlled self-assembly of nucleotidelanthanide complexes: specific formation of nanofibers from dimeric guanine nucleotides. Chem Commun. 2008:6534-6536.

66. Brindle K. New Approaches for imaging tumour responses to treatment. Nat Rev Cancer. 2008; 8:94-107. [PubMed: 18202697]

67. Yu SB, Watson AD. Metal-Based X-ray Contrast Media. Chem Rev. 1999; 99:2353-2378. [PubMed: 11749484]

\section{Biographies}

Joseph Della Rocca received a B.A. in Chemistry in 2007 from Middlebury College working under Professor Sunhee Choi. Currently, he is a doctoral student in chemistry at the University of North Carolina at Chapel Hill under Professor Wenbin Lin. His research is focused on the development of hybrid nanomaterials for drug delivery.

Demin Liu obtained a B.S. degree in Chemistry from Xiamen University (Xiamen, China) in 2009. Currently, he is a doctoral student in chemistry at the University of North Carolina at Chapel Hill under the direction of Professor Wenbin Lin. His research interest lies in the development NMOFs and other hybrid nanoparticles for bioimaging and drug delivery.

Wenbin Lin obtained a B.S. degree from the University of Science and Technology (Hefei) in 1988 and received a Ph.D. degree in chemistry from the University of Illinois at UrbanaChampaign in 1994. He was a NSF postdoctoral fellow at Northwestern University, and he became an assistant professor of chemistry at Brandeis University in 1997. He moved to the University of North Carolina in 2001 and was promoted to associate and full professor of chemistry in 2003 and 2007. He has published over 170 papers and won numerous professional honors. 


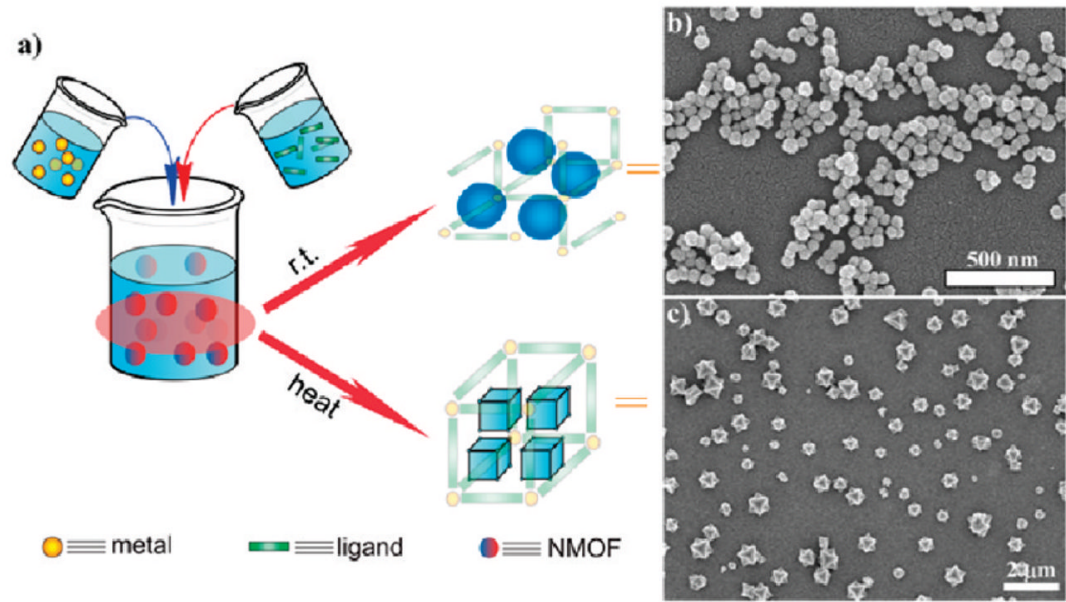

FIGURE 1.

(a) Surfactant-free synthesis of NMOFs by simply mixing NMOF precursors in appropriate solvents. In the nanoprecipitation method, the NMOF forms rapidly at r.t., whereas in the solvothermal method heating the solution leads to more controlled NMOF particle growth. (b, c) SEM images of (b) amorphous NMOF $\mathbf{1}^{24}$ and (c) crystalline NMOF $2 .{ }^{25}$ 


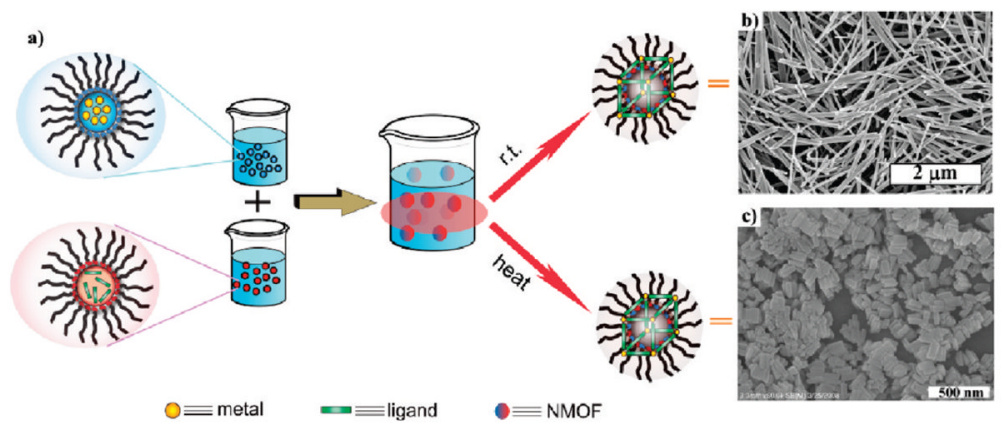

FIGURE 2.

(a) Surfactant-templated NMOF synthesis, either based on reverse microemulsions at r.t. or based on surfactant-assisted solvothermal reactions. (b, c) SEM images of crystalline particles (b) $\mathbf{3}^{28}$ and (c) $\mathbf{5},{ }^{29}$ respectively. 
a)

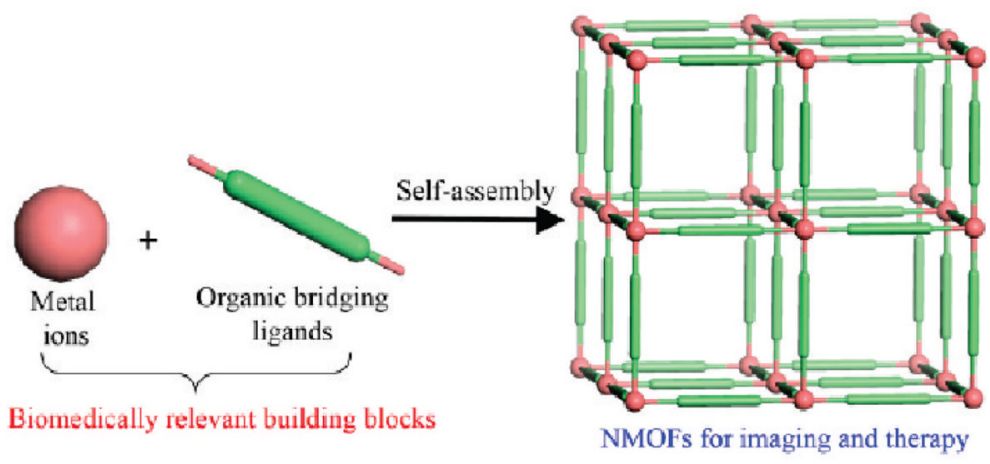

b1)
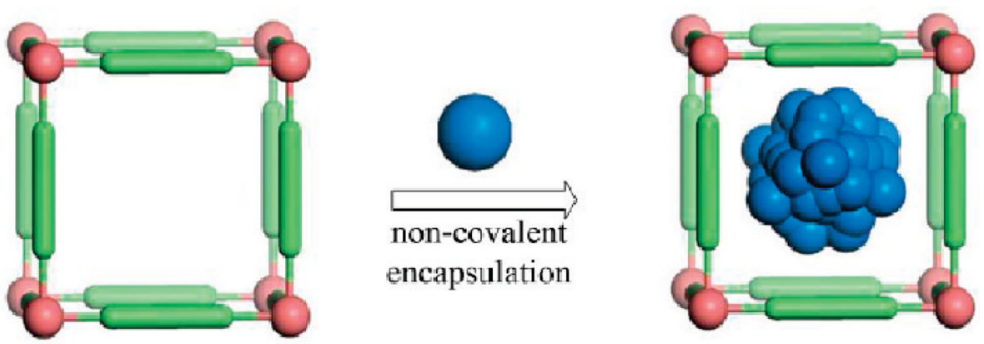

b2)
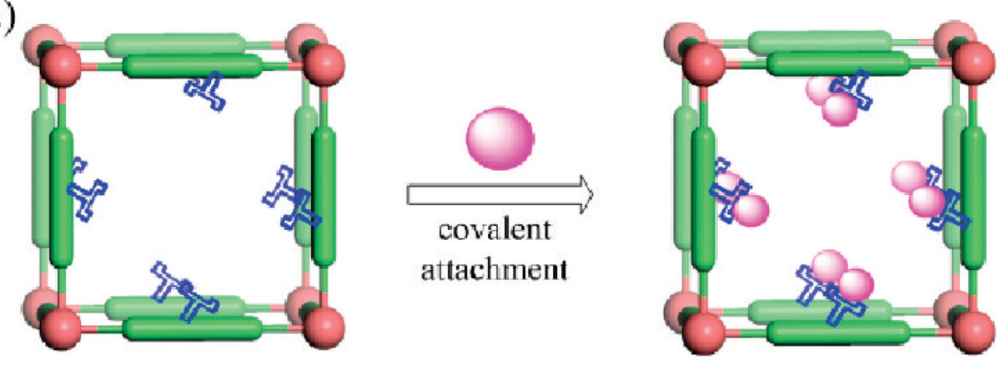

FIGURE 3.

Schematics showing the strategies for incorporating biomedcially relevant agents into NMOFs. (a) Direct incorporation of biomedically relevant metal connecting points or bridging ligands. (b1) Postsynthesis encapsulation via noncovalent interactions. (b2) Postsynthesis incorporation via covalent attachment. 

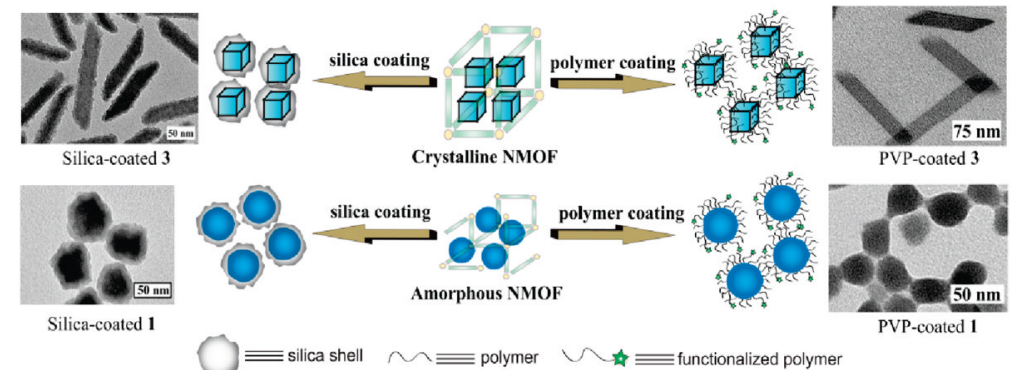

FIGURE 4.

Schematic showing surface functionalization of crystalline and amorphous NMOFs with either a thin shell of silica or with polymer coatings. TEM images of representative silicaand PVP-coated NMOFs are also shown. Reproduced with permission from refs 24 and 46. Copyright 2008 and 2007 American Chemical Society. 

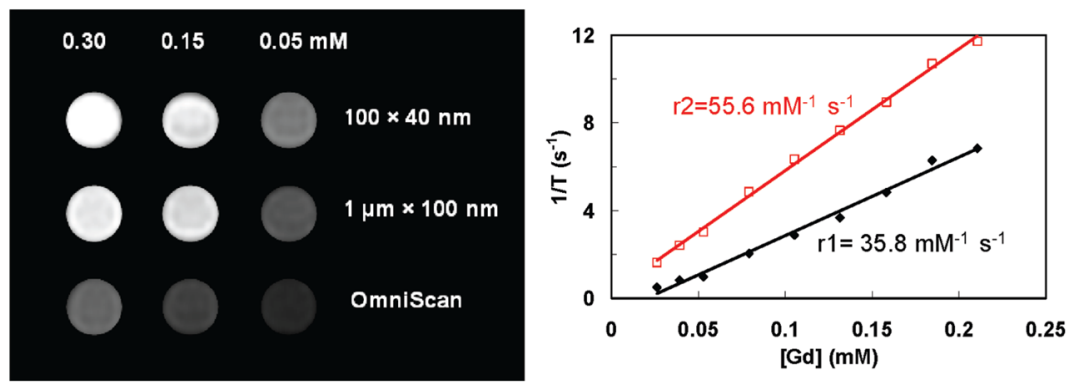

FIGURE 5.

Left: $\mathrm{T}_{1}$-weighted MR phantoms of $\mathbf{3}$ in water with $0.1 \%$ xanthan gum at $3 \mathrm{~T}$. Right: $\mathrm{r}_{1}$ and $\mathrm{r}_{2}$ relaxivity curves of $\mathbf{3}$ of $\sim 100 \mathrm{~nm}$ in length by $\sim 40 \mathrm{~nm}$ in diameter. Reproduced with permission from ref 28. Copyright 2006 American Chemical Society. 

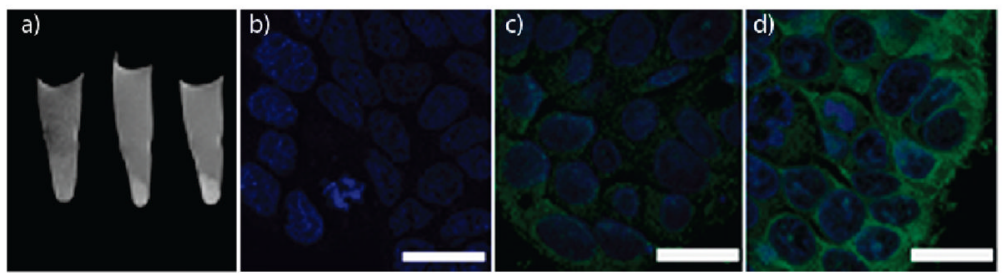

FIGURE 6.

(a) In vitro MR images of HT-29 cells incubated with 7@ silica (left), nontargeted 7@ silica (middle), and c(RGDfK)-targeted $7 @$ silica (right). Confocal images of HT-29 cells incubated with no particle (b) nontargeted 7@ silica (c), and c(RGDfK)-targeted 7@ silica (d). The cell nuclei were stained with DRAQ5 (blue), and the particles were detected with rhodamine B (green). Scale bars represent $20 \mu \mathrm{m}$. Reproduced with permission from ref 32. Copyright 2008 American Chemical Society. 

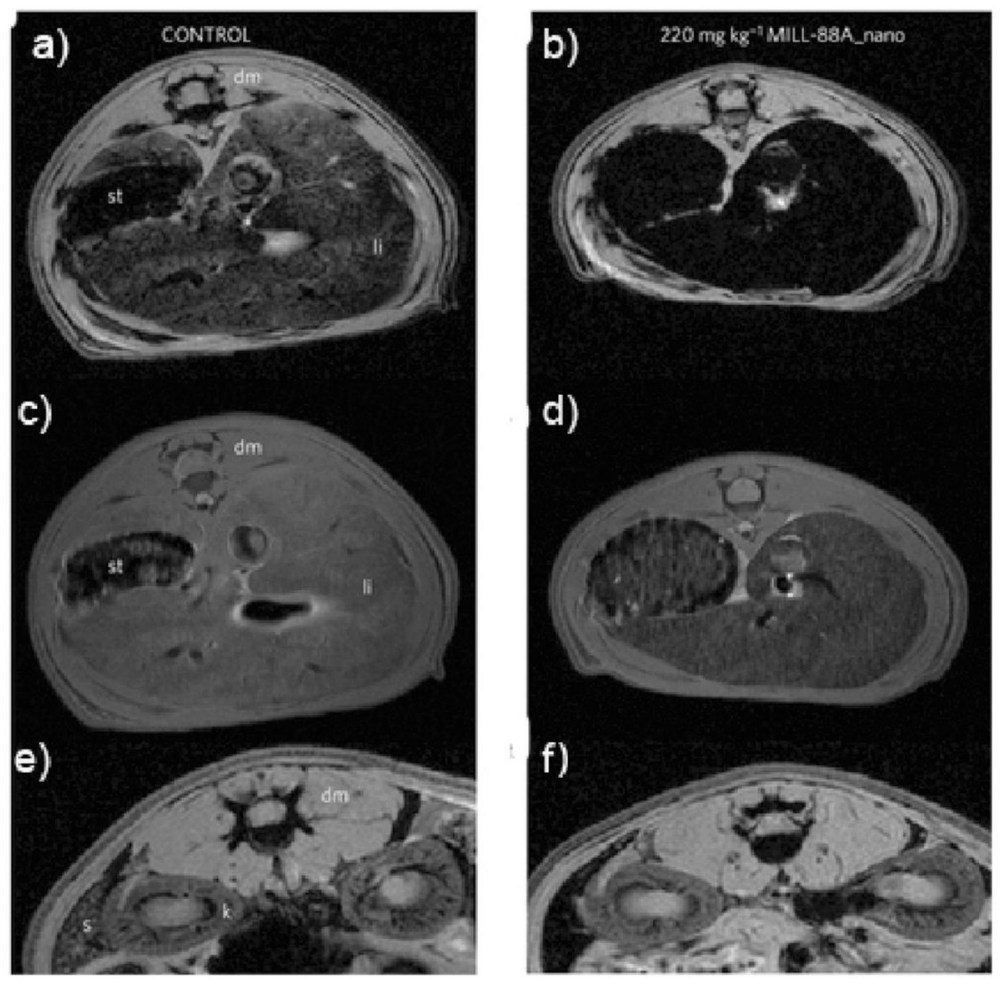

FIGURE 7.

$\mathrm{T}_{2}$ weighted MR images of Wistar rats injected with no particle (a,c,e) or $220 \mathrm{mg} / \mathrm{kg} 9$ $(\mathrm{e}, \mathrm{d}, \mathrm{f})$. The images were acquired using either gradient echo (a,b,e,f) or spin echo (c,d) sequences. The images show the liver $(\mathrm{a}-\mathrm{d})$ or spleen $(\mathrm{e}, \mathrm{f})$ regions $30 \mathrm{~min}$ postinjection. [dm $=$ dorsal muscle, $\mathrm{k}=$ kidney, $\mathrm{li}=$ liver, $\mathrm{s}=$ spleen, $\mathrm{st}=$ stomach]. Reproduced with permission from ref 30. Copyright 2010 Nature Publishing Group. 

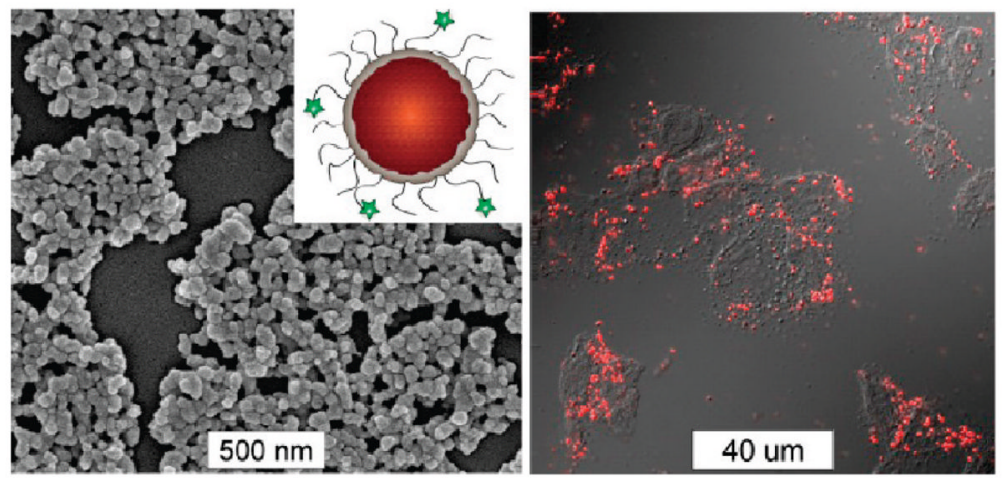

FIGURE 8.

Left: SEM image of anisamide-targeted and silica-coated particles of $\mathbf{1 5}$. The inset shows the schematic of such core-shell nanoparticles. Right: Confocal microscopy image of H460 cell after incubated with anisamide-targeted and silica-coated particles of $\mathbf{1 5}$. Reproduced with permission from ref 64. Copyright 2011 John Wiley and Sons. 

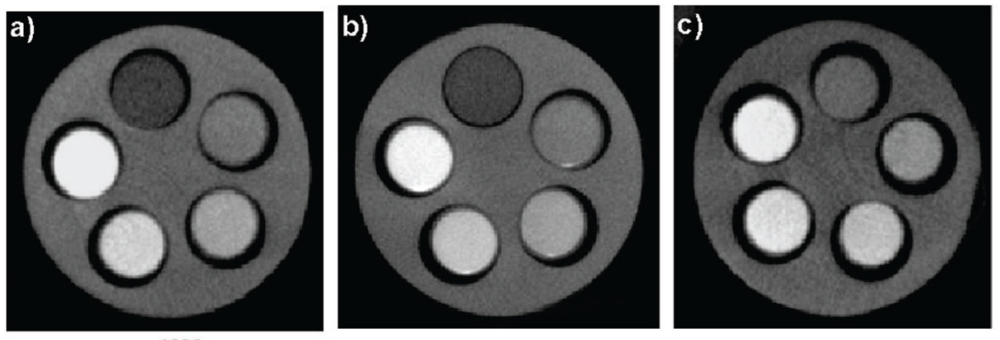

d)

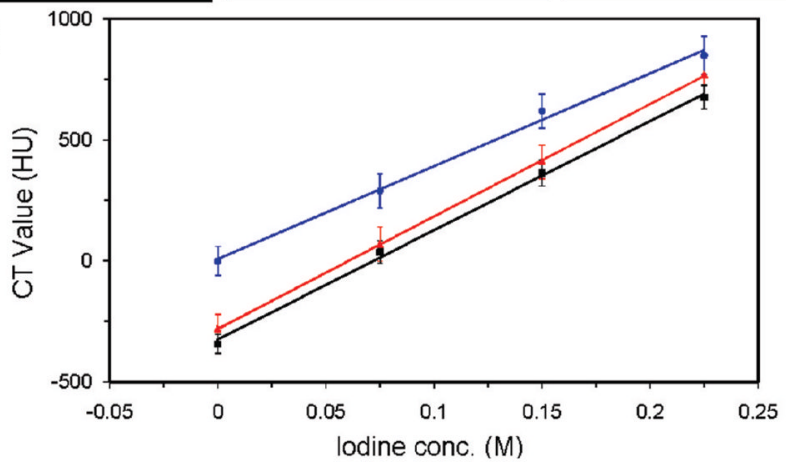

FIGURE 9.

CT phantom images of $\mathbf{1 7}$ (a), 18 (b), and iodixanol (c). 17 and 18 were dispersed in ethanol, and iodixanol was dissolved in water. From the top, clockwise, the slots have $[\mathrm{I}]=0,0.075$, $0.150,0.225$, and $0.300 \mathrm{M}$. (d) X-ray attenuation as a function of [I] for $\mathbf{1 7}$ at $40 \mathrm{kVp}, \mathbf{1 8}$ at $50 \mathrm{kVp}$, and iodixanol at $40 \mathrm{kVp}$. Reproduced with permission from ref 33. Copyright 2009 John Wiley and Sons. 


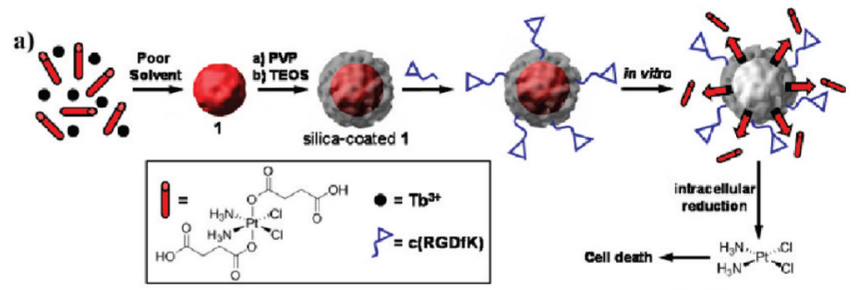

b)

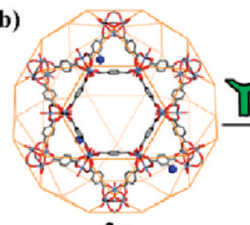

2a
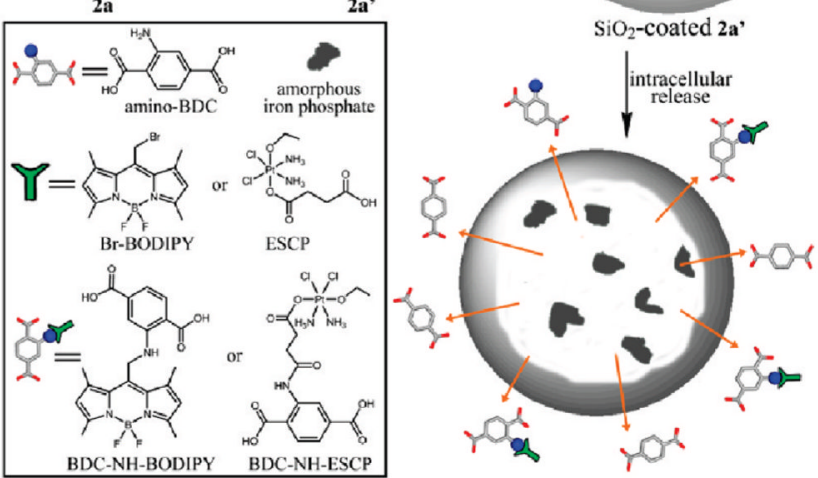

FIGURE 10.

Schematic representations of the synthesis, modification, and cisplatin release from $\mathbf{1}$ (a) and 2a (b). The cisplatin prodrug was loaded into $\mathbf{1}$ by direct incorporation (a) or into $\mathbf{2}$ by postsynthesis covalent attachment (b). Reproduced with permission from refs 24 and 25. Copyright 2008 and 2009 American Chemical Society. 

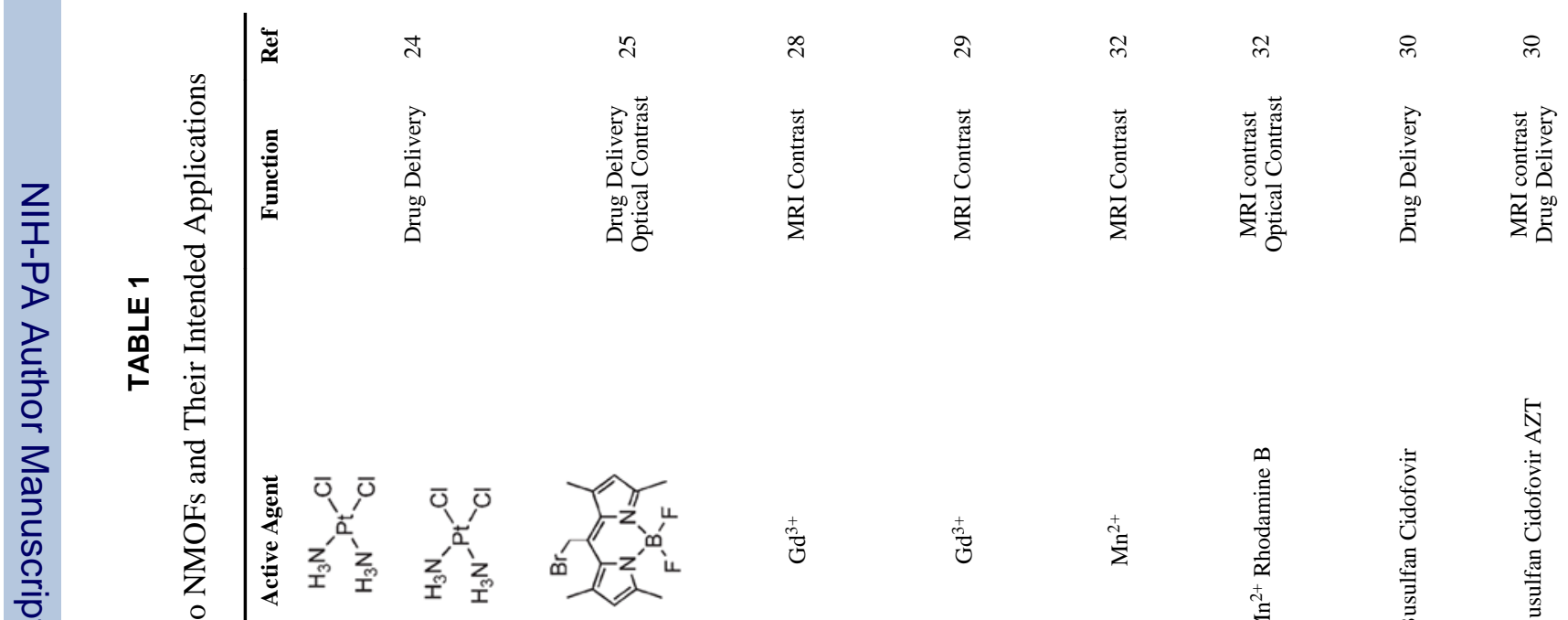

孛

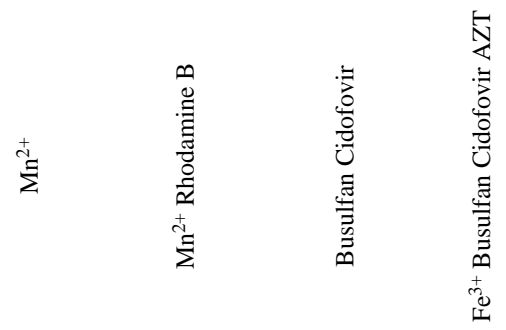

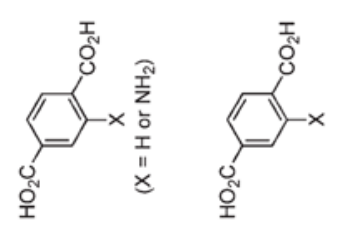

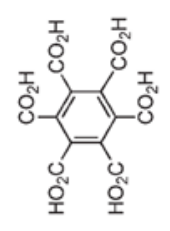<smiles>COc1ccc(OC)cc1</smiles><smiles>COc1cc(OC)cc(OC)c1</smiles><smiles>COC(=O)CC=CC(C)=O</smiles><smiles>CC(=O)CCCC(=O)O</smiles>

s 


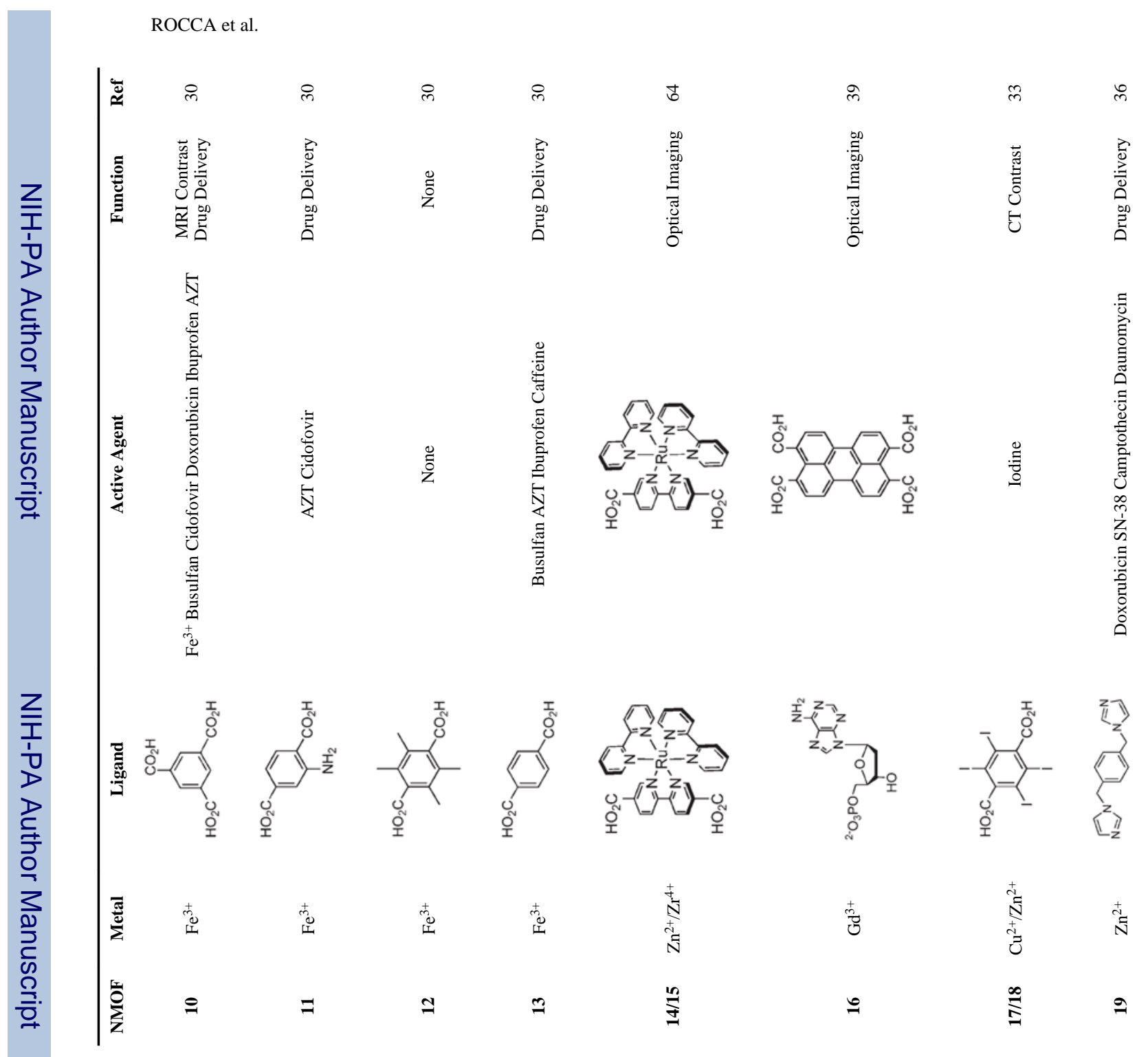


TABLE 2

MR Relaxivity Values of NMOFs on a per Metal Basis ${ }^{a}$

\begin{tabular}{llrc}
\hline NMOF $($ dimensions $)$ & field strength & $\mathbf{r}_{\mathbf{1}}\left(\mathbf{m M}^{-\mathbf{1}} \mathbf{s}^{\mathbf{- 1}}\right)$ & $\mathbf{r}_{\mathbf{2}}\left(\mathbf{m M}^{\mathbf{- 1}} \mathbf{s}^{\mathbf{- 1}}\right)$ \\
\hline $\mathbf{3}(100 \times 400 \mathrm{~nm})^{28}$ & $3 \mathrm{~T}$ & 35.8 & 55.6 \\
$\mathbf{3}(400 \times 700 \mathrm{~nm})^{28}$ & $3 \mathrm{~T}$ & 26.9 & 49.1 \\
$\mathbf{3}(1000 \times 100 \mathrm{~nm})^{28}$ & $3 \mathrm{~T}$ & 20.1 & 45.7 \\
$\mathbf{4}(100 \times 25 \mathrm{~nm})^{28}$ & $3 \mathrm{~T}$ & 13.0 & 29.4 \\
Omniscan & \\
$\mathbf{6}(50-100 \times 750-3000 \mathrm{~nm})^{32}$ & $3 \mathrm{~T}$ & 4.1 & \\
$\mathbf{7}(50-300 \mathrm{~nm})^{32}$ & $3 \mathrm{~T}$ & 5.5 & 80.0 \\
$\mathbf{7}(50-300 \mathrm{~nm})^{32}$ & $9.4 \mathrm{~T}$ & 7.8 & 70.8 \\
$\mathbf{7} @$ silica $(50-300 \mathrm{~nm})^{32}$ & $9.4 \mathrm{~T}$ & 4.6 & 141.2 \\
$\mathbf{9}(150 \mathrm{~nm})^{30}$ & $9.4 \mathrm{~T}$ & 4.0 & 112.8 \\
PEG-9 $(150 \mathrm{~nm})^{30}$ & $9.4 \mathrm{~T}$ & & 56 \\
$\mathbf{1 0}(200 \mathrm{~nm})^{30}$ & $9.4 \mathrm{~T}$ & & 95 \\
PEG-10 $(200 \mathrm{~nm})^{30}$ & $9.4 \mathrm{~T}$ & & 73 \\
\hline
\end{tabular}

${ }^{a}$ Omniscan is a clinically used small molecule Gd complex. 